\title{
BUSINESS MODEL TRANSFORMATION IN THE GERMAN ENERGY SECTOR: KEY BARRIERS AND DRIVERS OF A SMART AND SUSTAINABLE TRANSFORMATION PROCESS IN PRACTICE
}

\author{
Denise Meyer*, Jan Fauser*, Dieter Hertweck* \\ *Reutlingen University, Faculty of Computer Science and Reutlingen Research Institute
}

KEYWORDS: Barriers, business model transformation, drivers, expert interview study, smart energy, sustainable business models.

\begin{abstract}
:
The energy sector in Germany, as in many other countries, is undergoing a major transformation. To achieve the climate targets, numerous measures to implement smart energy and resource efficiency are necessary. Therefore, energy companies are experiencing increasing pressure from politics and society to transform their business areas in a sustainable manner and implement smart and sustainable business models. Consequently, numerous resources are expected to flow into the development and implementation of new business models. But often these efforts remain unsuccessful in practice. There is a large amount of literature on barriers and drivers of smart and sustainable business models in the energy sector. But what are the factors that companies struggle with most when developing and implementing new business models in practice? To answer this question, the results of a systematic literature review were evaluated by conducting semi-structured interviews with experts of the German energy sector. Six categories of transformation barriers were identified: Organizational, Financial, Legal, Partner-Network, Societal and Technological barriers. To overcome these barriers, recommendations for action and key success factors are outlined by the experts interviewed. The interview study validates key barriers and drivers in terms of their significance in practice in the German energy sector and makes recommendations to advance the smart and sustainable transformation of the energy sector.
\end{abstract}

\section{INTRODUCTION}

The energy turnaround in Germany and the digitization mean a radical technical change from centralized to decentralized and smart energy production. The long-established structures of energy production in large plants and conventional distribution networks which allowed stable economies of scale and low unit costs are over (Doleski, 2014). Digitization is increasingly transforming the energy sector. Digital technologies change business models, provide new value propositions and generate new revenues. The energy generation of the future with renewable energies must be managed flexibly, decentrally and in an intelligent manner, and this can only be achieved with the help of smart technologies. The need for smart energy management is also emphasized in the context of smart cities. Energy supply and demand must be smartly balanced, smart grids need to be created, and smart data flows must be generated. During this intelligent and sustainable transformation of the energy sector, key barriers and drivers need to be addressed.

Key drivers such as technological progress in energy generation, storage or control, but also organizational and cultural change through re-municipalization, strong citizen participation or the development of consumers into prosumers, have massively changed the structure of the energy industry in the course of the energy turnaround. The growth of renewable energies and new technologies creates new business model opportunities. These driving factors force many companies in the energy domain to develop new business models. But during the development and implementation process of new business models in established energy organizations a variety of barriers need to be addressed. For instance, according to Burger and Luke (2017) the influence of regulation is greater than the influence of technology in the industry.

In this paper we conducted an interview study on barriers and drivers and their impact on the development and implementation of new business models. Therefore, this study deals with the research question: What are the barriers and driving factors of a smart and sustainable business model transformation in the German energy sector? The objective of the interview study was to validate findings from different literature reviews and case studies and to examine their external validity for key actors in the German energy domain.

The paper is structured as follows: In section 2 we give a short overview on related work. We describe the methodology in section 3, before displaying the results in chapter 4 . In section 5 we discuss the results and finally we give an overview of the main findings and outline further research in section 6 .

\section{BACKGROUND}

In this chapter we describe different key barriers and drivers from literature for the development of new business models in the energy domain. There is no consistent definition of the term "business model" in the scientific literature. According to the definition by Osterwalder et al. (2010) "a business model describes the rational of how an organization creates, delivers, and captures value." Many companies are trying to develop new business models, but only a few of them are successfully implemented (Echterhoff, Hirschter and Gausemeier, 2016). A business model must prove that it is technically and legally feasible, economically viable, and that customers are willing to pay for it. The term "energy system" in this context must be understood in a broader context that includes raw materials, resources, technologies, economics, society, and law. These are all crucial factors that have a decisive influence on the energy system in direct or indirect ways.

Financial and Economic drivers and barriers are central barriers in the field of renewable energy business models, first and foremost high up-front investment costs and long amortization periods (Ruggiero, Varho and Rikkonen, 2015; Engelken et al., 2016; Zhang et al., 2017). Another financial barrier is the lack of financial governmental long term support (Ojala, 2001). According to Kotilainen and Sommarberg (2016), Engelken et al. (2016), Horváth and Szabó (2018), and Eleftheriadis and Anagnostopoulou (2015) the overarching regulations in the energy sector are creating additional 
complexity and bureaucracy. The constantly changing regulation in the domain of renewable energies makes long term planning, building and operating complex value networks with many actors difficult; but a long-term perspective is necessary for the energy system to function effectively (Richter, 2011; Aslani and Mohaghar, 2013; Engelken et al., 2016). As a result, Engelken et al. (2016) describe budget problems and a limitation of growth for renewable energies. On the other hand, economic drivers such as low marginal costs of energy from renewable energies help drive new business models (Engelken et al., 2016). Another important driver are subsidies as part of the energy turnaround supported by policymakers. An additional driver, which is discussed in the scientific literature, is sector coupling. This describes the development of linking the sectors of power and heat supply, mobility and industrial processes as well as their infrastructures, which could be the key to a successful energy turnaround.

There are a variety of organizational barriers for developing and implementing new business models in established organizations. Chesbrough (2010) describes that there are conflicts between an existing business model and a new innovative business model, as they compete and could corrupt each other. According to Dewald (2018) the adoption of a new business model is confronted with multiple barriers, but none more significant than managers' cognitive barriers to change. Chesbrough (2010) supports this thesis by describing that manager's often stick to their traditional structures, because of their skepticism that change might threaten the core value of their company. According to Kotilainen and Sommarberg (2016) and Richter (2013b) business model innovation is not part of the "corporate DNA" of a traditional energy supplier. Thus, utility providers traditionally do not seem to be first movers, as they carry a lot of internal resistance to innovation and change (Richter, 2013a). Another issue is the lack of communication or transparency about the new business model. This can lead to emerging concern among employees about their job security or, if the business model is not fully understood, even to its rejection in management circles.

Horváth and Szabó (2018) and Zhang et al. (2017) mention the integration of renewable energies into energy systems as an obstacle. The security of supply and the risk of poor system performance is one of the greatest technological challenges in the development of business models for photovoltaic technologies (PV). According to Eleftheriadis and Anagnostopoulou (2015) the insufficient development of electricity grids is one of the problems in the development of regenerative energy sources. Especially in the field of wind power, areas with high wind potential are neither connected to the mainland grid nor can the generated energy be distributed efficiently because of a lack of technical infrastructures. On the other hand, a key driver for the growing acceptance for renewable energy is the technological progress and decreasing cost of technologies.

The threat of the negative effects from climate change is the most influential drivers to implement $\mathrm{CO}_{2}$ reduction goals and to support measures to mitigate climate change (Engelken et al., 2016; Chang et al., 2011; Jolly, Raven and Romijn, 2012). The Kyoto protocol and the Paris Agreement strongly influenced regulatory adjustments in energy policies. These are key drivers for business model innovation. According to Funkhouser et al. (2015), Bocken et al. (2014) Engelken et al. (2016) another central aspect is customers' demand for smart and sustainable products and services and the resulting changes in business models. Richter (2013b) describes a central barrier in public acceptance the "not in my back yard" (NIMBY) effect. This describes the citizens' resistance against grid expansion and new renewable energy projects in their immediate surroundings
(Reiche and Bechberger, 2004). The NIMBY effect is caused by citizens' concerns about health risks, noise, distances to residential buildings, interference with the residential buildings, or impairment of the landscape (Mautz, 2006). Mautz (2006) describes a further concerning issue the decrease in value of real estate within private households especially in the close range of wind turbines. Richter (2013b) furthermore points out that customer interest in innovative business models is limited, for example in the case of the residential heating business model, which is often offered to customers as a full-service package at a fixed price. Customers are not interested in committing to an energy supplier in the long term, since a possible drop in stock market prices could mean that they pay higher prices in a longterm contract than when they switch providers (Richter, 2013b).

\section{METHODOLOGY}

Based on the results of a German research project in the field of 'energy generation and distribution of the future' and our previous extensive literature review (Fauser et al., 2019), an interview study was conducted. The aim was to identify relevant barriers and drivers in the development and implementation of new business models in the energy sector in Germany. The framework was designed to summarize and clearly present barriers and drivers from different areas to provide practitioners, researchers and legislators with a basis for decision-making. To our knowledge, there exists no such up-to-date framework for the German energy market.

Based on the results from the literature, a guideline with eight core questions was developed. The questions addressed financial, change management, competency, technological, market and regulatory factors, and were pretested for comprehensibility and clarity by student participants. The final interview questions are not presented here due to space limitations but can be gladly provided by the authors upon request. Subsequently, 25 local experts from the energy generation and energy service sectors were contacted by mail, of which nine experts agreed to participate in the study. Individual 60-90-minute semi-standardized interviews were conducted. The interviews were recorded and subsequently transcribed using MAXQDA2020.

After transcription, the interviews were analyzed according to Kuckartz's (2014) Qualitative Content Analysis, which is a content-structuring content analysis. The concrete analysis took place in MAXQDA2020 and consisted of three multiphase steps in each case. In the first step, the data was prepared through initiating text work, deductive codes were developed from the research questions and guidelines, followed by the coding of part of the interviews with the deductive codes and the generation of additional inductive codes. Using the revised deductive-inductive code system, all codes were summarized and paraphrased to ensure equal understanding of the codes by the raters. All interviews were coded by two independent raters. Discrepancies in the coding were discussed and adjusted accordingly. In the second step, the content structuring analysis followed, whereby a case-based as well as a code-based qualitative analysis incl. context analysis was carried out to obtain a thematically structured presentation of the results. Finally, in the third step, the evaluative analysis followed, whereby the paraphrases and formulations of statements of the evaluation categories were screened and cases were assigned to individual statements. This resulted in the comparative interpretation and simple statistical evaluation by creating comparative descriptive analyses of the two groups: energy producers vs. energy consultants. The results of these analyses are presented in the following section. 


\section{RESULTS}

Expert interviews were conducted to analyse best practice projects and to identify relevant barriers and success factors. Nine experts from the energy domain were interviewed, among them five experts from the energy supply sector and four experts from the energy consulting / service sector. The aim of the study was to identify which new business models companies have developed and implemented as a response of the energy turnaround and digitization. One focus was on the analysis of best practice projects and thus on particularly innovative and successful business models that could have a trend-setting signal effect for numerous follow-up projects in the context of the energy turnaround. To develop a practice-relevant implementation roadmap, the interviews also focused on identifying success factors (drivers) and barriers. It was analysed which drivers could be used and which barriers should be overcome to promote the successful development and implementation of new business models.

\subsection{New business models}

Various business models from the areas of heat supply, power supply, e-mobility, infrastructure as well as new business models in the context of cross-company-value-networks were described as new business models in the field of renewable energies and in the operation of decentralized networks.

Altogether it appears that the companies are tackling various new business models in the areas mentioned, but their focus is still on established and well-tried business models. The surveyed energy suppliers saw the liberalization of the electricity market as an opportunity for their companies. They named the transition from the business model of "monopolylike provision of heat and electricity" to alternative products and services as a challenge that must be overcome. Some companies proved to be more "open to innovation" than others, which was illustrated by stronger efforts and higher investments in the development of sustainable business models.

In the field of power supply, all companies were committed to alternative business models, with the development of PV business models and data-driven business models being the focus in most cases. The topic of e-mobility was also well received by most utility providers (4/5), with the surveyed companies focusing on sharing business models and the provision of an e-charging infrastructure. Two of the five utility providers surveyed also mentioned their commitment to building infrastructure in areas that were not previously part of their field of business (including the expansion of broadband and fiber optics and the expansion of LoRaWAN networks). Only two of the five utility providers mentioned new business models around heat supply as a focus, with one case referring to the operation of a combined heat and power (CHP) or biogas plant.

In addition, all companies surveyed also described that they generally develop new business models in cross-company projects or enter cross-company partnerships for sub-projects. The development and implementation of new business models therefore usually takes place within the framework of complex value networks.

\subsection{Barriers}

In the area of barriers, the barriers identified in the systematic literature analysis were largely confirmed. Table 1 displays the main barriers with their respective subcategories sorted in descending relevance. The numbers represent the number of mentions in the interviews by the respective group of experts.
Organizational barriers were named by the respondents as the top priority, i.e. barriers that arise due to internal company conditions. The first point of criticism was the organizational structure of the companies. Not enough personnel resources were made available for the development and implementation of new business models and employees were usually too busy in their daily business to address such issues on the side. In addition, the structures and processes in the company are too complex and slow, and there is a lack of flexible processes and standards to develop new business models in an agile way. A conservative corporate culture, which slows down the development of new business models, was cited just behind this. In this context, the interviewees described a corporate culture that is shy of change, which manifests itself in an aversion to all kinds of change and risk. In addition, the respondents cited a lack of competencies within the company among the organizational barriers. One participant described the problem as "So you simply need specialists on the one hand who are proficient in certain topics, and on the other hand you need generalists who can think the big picture. And this combination does exist, but it is very expensive. And it often ends up with the large corporation and not with the municipal energy supplier." As specific missing competencies, they named IT competencies and methodological competencies around (customer-centric) business model development.

Financial and economic barriers were named after the organizational barriers. Among these, the respondents cited first and foremost a lack of financial resources available for the development and implementation of new business models. The reasons for this were high investment costs, long amortization periods and the resulting lack of financing models. In second place, they cited strong competition - because of the liberalization of the electricity market - which manifests itself in strong price pressure from competitors, declining margins and high costs for customer acquisition and retention. One participant explained "We have noticed since the liberalization of the electricity market that the fluctuation of customers is increasing and that we have to invest more money to get customers. Especially due to all these online price comparison portals." The respondents also cited a lack of financial foresight regarding the sustainability of business models. They also cited competition between new business models and established business models in the commodities sector. This prevents some companies from establishing new business models that could replace existing ones.

Legal and political barriers were mentioned in third place. Here it was precisely the issue of regulation that was considered an obstacle. In this context the respondents named counterproductive regulations (e.g., strict data protection requirements) and planning uncertainty due to changes in regulations that prevent the implementation of new business models. One participant explained the problem "This is due to the fast pace of change. If you look at all the new regulations that have been introduced in the energy sector in recent years, the pace is relatively high compared with other sectors. Of course, this is associated with a corresponding degree of uncertainty." In addition, (complex) ownership structures, lack of financial incentives and high taxes were named as barriers. It was criticized that regulation intervenes too much in the market and hinders innovation.

In fourth place, partner-network-related barriers were mentioned. Barriers caused by partner networks are those barriers that arise when partnerships and when value networks are formed with external parties (e.g., partners, service providers, start-ups, etc.). In this context, the dependency on external partners was criticized above all: "We are dependent on various IT service providers, who then actually build the 
application. And [...] if provider XY drops out, then [...] sooner or later my entire interface will lie inactive." This demonstrated itself on the one hand to the difficulty of finding reliable partners and on the other hand to a certain degree of planning uncertainty associated with the involvement of an external partner. In addition, conflicts of mentality and interests of the partners were cited as an obstacle. In this context, differences in mentality regarding work processes/methods, transparency, data protection and a lack of commitment to actively participate in the network were mentioned. In addition, the complexity of cross-company networks of different partners and the resulting intransparency of processes was named as a barrier.

\begin{tabular}{|c|c|c|c|}
\hline & & $\begin{array}{l}\text { Energy } \\
\text { Supplier } \\
(n / \%)\end{array}$ & $\begin{array}{l}\text { Energy } \\
\text { Consulting } \\
(n / \%)\end{array}$ \\
\hline \multirow{4}{*}{$\begin{array}{l}\text { Organizational } \\
\text { barriers }\end{array}$} & & $57 / 37.3 \%$ & $33 / 24.3 \%$ \\
\hline & $\begin{array}{l}\text { Organizational } \\
\text { structure }\end{array}$ & 23 & 13 \\
\hline & $\begin{array}{l}\text { Conservative corporate } \\
\text { culture }\end{array}$ & 21 & 11 \\
\hline & $\begin{array}{l}\text { Lack of certain } \\
\text { competences }\end{array}$ & 13 & 9 \\
\hline \multirow{6}{*}{$\begin{array}{l}\text { Financial } \\
\text { barriers }\end{array}$} & & $30 / 19.6 \%$ & $35 / 25.7 \%$ \\
\hline & Lack of resources & 12 & 13 \\
\hline & Strong competition & 7 & 8 \\
\hline & $\begin{array}{l}\text { General financial } \\
\text { barriers }\end{array}$ & 6 & 4 \\
\hline & $\begin{array}{l}\text { Lack of sustainable } \\
\text { foresight }\end{array}$ & 1 & 7 \\
\hline & $\begin{array}{l}\text { Competition of existing } \\
\text { business models }\end{array}$ & 4 & 3 \\
\hline \multirow{3}{*}{$\begin{array}{l}\text { Legal / } \\
\text { Political } \\
\text { barriers }\end{array}$} & & $23 / 15.0 \%$ & $31 / 22.8 \%$ \\
\hline & Regulation & 20 & 25 \\
\hline & $\begin{array}{l}\text { Lack of political } \\
\text { guidance }\end{array}$ & 3 & 6 \\
\hline \multirow{4}{*}{$\begin{array}{l}\text { Barriers due } \\
\text { to partner } \\
\text { networks }\end{array}$} & & $28 / 18.3 \%$ & $14 / 10.3 \%$ \\
\hline & $\begin{array}{l}\text { Dependence on } \\
\text { partners }\end{array}$ & 16 & 1 \\
\hline & Mentality & 5 & 11 \\
\hline & $\begin{array}{l}\text { Complexity and lack of } \\
\text { transparency }\end{array}$ & 7 & 2 \\
\hline \multirow{4}{*}{$\begin{array}{l}\text { Structural / } \\
\text { societal } \\
\text { barriers }\end{array}$} & & $10 / 6.5 \%$ & $19 / 14.0 \%$ \\
\hline & $\begin{array}{l}\text { Lack of societal } \\
\text { interest/will }\end{array}$ & 7 & 13 \\
\hline & $\begin{array}{l}\text { Slow bureaucratic } \\
\text { processes }\end{array}$ & 1 & 5 \\
\hline & $\begin{array}{l}\text { Fast changing } \\
\text { environment }\end{array}$ & 2 & 1 \\
\hline \multirow{4}{*}{$\begin{array}{l}\text { Technological } \\
\text { barriers }\end{array}$} & & $5 / 3.3 \%$ & $4 / 2.9 \%$ \\
\hline & $\begin{array}{l}\text { Lack of IT } \\
\text { infrastructure }\end{array}$ & 4 & 0 \\
\hline & $\begin{array}{l}\text { Lack of key } \\
\text { technologies }\end{array}$ & 0 & 1 \\
\hline & None & 1 & 3 \\
\hline
\end{tabular}

Table 1. Main barriers with their subcategories $(n=$ the number of mentions of the specific barriers category by experts of the respective group, $\%=$ percentage share of the upper category in the total number of named barriers by the respective group).
Social and structural barriers were listed in fifth place. Among them, a lack of social will to support smart and sustainable business models was mentioned. This was explained by outdated views and a lack of acceptance of new technologies, a "Not in my back yard" (NIMBY) mentality of the citizens and a lack of willingness to pay for the products of the customers. One participant explained the problem in his word "The biggest barrier is the one that each of us carries around in our head. [...] That's why I always say to people, you first have to get the barriers out of your head and then we can talk." In addition, lengthy bureaucratic processes in contrast to a fast pace of development (technological, economic, political, etc.) were identified as a central obstacle in this context.

In last place, the respondents named technological barriers. The general consensus of the respondents was that in the vast majority of areas the necessary (key) technology is available and that it is only due to the legal, economic and social framework conditions that it is not applied across the board. One participant emphasized in this context: "I believe that if a good business model can emerge, then it is not the technology that is holding us back, as everything is available or can be done via any external partner." Another participant confirmed this: "That is not to be understood. So, we are technologically capable of solving things excellently, but somehow we don't want them to be solved." Only in one interview respectively did a lack of IT infrastructure (in the company) and the absence of central key technologies (hydrogen and Power-to-X innovations) come up for discussion.

In addition to the weighting of the individual codes, we conclude by discussing selected differences between the experts in the field of energy supply and energy consulting. In the case of financial barriers, it became apparent that energy consultants precisely criticized the lack of sustainable foresight on the part of companies; this problem was not recognized by the energy companies themselves. In the area of partner network barriers, it was found that the energy companies were primarily critical of their dependence on external partners, while the energy consultants were more critical of the mentality of the partners involved, which made an open exchange of ideas and constructive cooperation difficult in their opinion. In addition, energy consultants rated the importance of structural and societal barriers more highly than the energy companies themselves. The energy consultants described that they also considered contextual factors in their work and saw external factors, such as a lack of openness in society for green technologies, as significant, whereas the energy suppliers considered organizational and thus internal barriers to be central.

\subsection{Drivers}

In the area of success factors and drivers of new business models, the drivers identified in the systematic literature analysis were largely confirmed, whereby the individual weighting differed. Table 2 displays the main drivers with their respective subcategories sorted in descending relevance. The numbers represent the number of mentions in the interviews by the respective group of experts.

The respondents named organizational drivers in the first place when developing and implementing new business models. In terms of a company's understanding of service, they emphasized above all a customer/service focus, a focus on communication and education, and the importance of independent consulting as key drivers. In addition, they emphasized the importance of a sustainable orientation of the 
company and a corporate culture open to change as well as the agile adaptability of a company as central success factors. One participant explained: "Some [companies] are very agile and can of course always adapt to new market conditions and develop new business models, whether that's mobility topics or other energy-related services."

In second place, they emphasized partner-network related drivers as success factors in the development and implementation of new business models. The added value of external competences and expertise by outsourcing crucial process steps to external experts was mentioned. In this context, risk diversification for all parties involved was also emphasized and it was stressed that common standards can and should be defined. In addition, a cross-project exchange of experience and knowledge was also identified as a key success factor. Such networks would promote impulses for cooperation projects and, not least, innovation. One participant described the value of a network as follows: "A network naturally benefits from the fact that everyone contributes something, in whatever way. This can be customer references, projects, but of course it's also an exchange of knowledge and keeping each other informed. For me, networks also mean exchanging information and investing time."

In third place, the respondents emphasized financial drivers: Especially a profitable business model that is operated costefficiently, generates profits, and represents a (lateral) diversification of the company was named as a central driver. One participant described it as follows: "The goal, of course, must be that it does not become more expensive for the companies as a result. Cost savings are the basic prerequisite for something to be implemented at all." Furthermore, the importance of investors and especially investments in smart and sustainable technologies was emphasized as a decisive success factor.

In the context of the legal drivers in particular financial factors - such as the added value of long-term financial (planning) security through public funding and subsidies - were highlighted. In addition, regulations were named as innovation drivers, the subject of business/consulting models and the added value of actively helping to shape legislation.

The importance of external / societal drivers was also explained. In this context, an increased environmental awareness of the population was emphasized, which shapes the will and readiness to actively promote the energy turnaround. One participant described this change: "And that's the good thing, the population [...] simply has a different approach to the subject. They also want to make the energy transition work, so they also invest in the future." In addition, an openness to digitization and thus digital business models and digital technologies to enable the energy turnaround was named. Another point that was mentioned was an economic downturn as a beneficial external factor, which experience has shown that companies increasingly understand and pursue the need for (business model) innovations in times of economic recession.

The respondents did not explicitly put technological drivers in the foreground but emphasized that the technologies needed to implement a business idea are usually available. Especially smart technologies that address environmental and sustainability factors were highlighted. For example, one participant explained, "The cost has come down in that just the technology, like batteries, have a longer life today due to optimized application scenarios." In addition, a forward-looking transformation of the IT (infrastructure) and data-driven business models were seen as conducive to innovation.

Both groups saw organizational and thus internal success factors as most significant. Especially promising internal services and tasks, which direct the company to future tasks and the requirements of customers. The energy consultants assigned financial factors an equally high driving function. Profitable business models were said to have enormous potential for new business models, and financial security through public funding and subsidy was also assigned key importance in this context. The energy companies, on the other hand, did not see financial factors as central. In addition, external factors were also seen as more important by the energy consultants than by the energy companies, whose focus was once again more on corporate processes.

\begin{tabular}{|c|c|c|c|}
\hline & & $\begin{array}{l}\text { Energy } \\
\text { Supplier } \\
(n / \%)\end{array}$ & $\begin{array}{l}\text { Energy } \\
\text { Consulting } \\
(n / \%)\end{array}$ \\
\hline \multirow{4}{*}{$\begin{array}{l}\text { Organizational } \\
\text { drivers }\end{array}$} & & $12 / 34.3 \%$ & $15 / 28.3 \%$ \\
\hline & $\begin{array}{l}\text { Promising services and } \\
\text { tasks }\end{array}$ & 9 & 11 \\
\hline & $\begin{array}{l}\text { Future-oriented } \\
\text { corporate culture }\end{array}$ & 3 & 3 \\
\hline & Agile adaptability & 0 & 1 \\
\hline \multirow{3}{*}{$\begin{array}{l}\text { Partner network } \\
\text { related drivers }\end{array}$} & & $9 / 25.7 \%$ & $8 / 15.1 \%$ \\
\hline & $\begin{array}{l}\text { Inclusion of external } \\
\text { expertise }\end{array}$ & 6 & 4 \\
\hline & $\begin{array}{l}\text { Exchange of knowledge / } \\
\text { experience }\end{array}$ & 3 & 4 \\
\hline \multirow{3}{*}{$\begin{array}{l}\text { Financial/ } \\
\text { Economic } \\
\text { drivers }\end{array}$} & & $1 / 2.9 \%$ & $14 / 26.4 \%$ \\
\hline & $\begin{array}{l}\text { Profitable business } \\
\text { model }\end{array}$ & 1 & 10 \\
\hline & $\begin{array}{l}\text { Investors / investment } \\
\text { activity }\end{array}$ & 0 & 4 \\
\hline \multirow{4}{*}{$\begin{array}{l}\text { Legal / Political } \\
\text { drivers }\end{array}$} & & $7 / 20.0 \%$ & $7 / 13.2 \%$ \\
\hline & $\begin{array}{l}\text { Financial security } \\
\text { through funding / } \\
\text { subsidy }\end{array}$ & 3 & 6 \\
\hline & $\begin{array}{l}\text { Innovation due to } \\
\text { regulations }\end{array}$ & 4 & 0 \\
\hline & $\begin{array}{l}\text { Involvement in shaping } \\
\text { legislation }\end{array}$ & 0 & 1 \\
\hline \multirow{4}{*}{$\begin{array}{l}\text { External / } \\
\text { societal drivers }\end{array}$} & & $3 / 8.6 \%$ & $7 / 13.2 \%$ \\
\hline & $\begin{array}{l}\text { Social will / } \\
\text { environmental awareness }\end{array}$ & 3 & 5 \\
\hline & Openness to digitization & 0 & 1 \\
\hline & Economic downturn & 0 & 1 \\
\hline \multirow{4}{*}{$\begin{array}{l}\text { Technological } \\
\text { drivers }\end{array}$} & & $3 / 8.6 \%$ & $2 / 3.8 \%$ \\
\hline & $\begin{array}{l}\text { Sustainable and smart } \\
\text { technologies }\end{array}$ & 0 & 1 \\
\hline & $\begin{array}{l}\text { Forward-looking } \\
\text { transformation of IT }\end{array}$ & 1 & 0 \\
\hline & $\begin{array}{l}\text { Data-driven business } \\
\text { models }\end{array}$ & 0 & 1 \\
\hline
\end{tabular}

Table 2. Main drivers with their subcategories $(n=$ the number of mentions of the specific drivers category by experts of the respective group, $\%=$ percentage share of the upper category in the total number of named drivers by the respective group).

\section{DISCUSSION}

This article combines the views of experts of the field of energy supply and energy consulting regarding key barriers and drivers for business model innovation.

The first key outcome were organizational factors, which 
were especially important. The experts emphasized a lack of sufficiently well-trained specialists and a lack of willingness on the part of companies to further train their own staff. Financial reasons were not seen as decisive here, but the possibility of developing one's own personnel was not sufficiently considered. Instead, missing expertise was rather obtained from outside as needed, which, however, increased the dependence of the own company on external expertise. Furthermore, the companies stated that they did not have sufficient personnel or time resources internally, nor sufficient expertise and methods to develop new business models systematically. One potential solution here is structural change management with the goal of strategically aligning internal training. The essential prerequisite for this is a change in thinking on the part of the company's management, so that its own personnel are not recognized as a cost factor but as a value factor and are strategically integrated into the company's strategy. For this purpose, sufficient resources must be used for the qualification of the company's own employees instead of simply buying in expertise from outside.

Partner network-related factors, a special form of organizational factors that are particularly important for new network business models, were also seen as central by the experts. Networks are becoming increasingly important, especially in view of the growing interconnectedness and complexity of business areas (Peppard and Rylander, 2006; Hellström et al., 2015; Koppenhöfer, Fauser and Hertweck, 2017). To stay on top of this type of new business model, energy companies should definitely involve experienced network management partners. In addition, it is of great importance to transparently present responsibilities and dependencies, e.g., critical points in the supply chain. Business ecosystems can be used for this purpose (Koppenhoefer, Fauser and Hertweck, 2018)

To address financial factors such as increasing price pressure and declining profits in the utility sector and simultaneously high upfront costs of new business models, new business models must be developed in a lean, agile, and customer-centric manner. By strategically developing new business models according to scientifically established methods (Osterwalder $e t$ al., 2010, 2014; Wirtz and Daiser, 2018), business models can be tested earlier, can be adapted iteratively, and thus reduce the risk of an expensive failure of a business model that has already been completely built. In order to compensate the initial capital or initial price differences of smart and sustainable business models, public subsidies, certificates or $\mathrm{CO}_{2}$ taxes play a decisive role (Engelken et al., 2016).

Legal factors, in particular public funding, were described by the experts as both a curse and a blessing. For legal factors to become a clear support factor for smart and sustainable business models, long-term planning security must be ensured by the funding programs (Engelken et al., 2016). This means extending expiring funding models in a timely manner or providing information about alternative models. For instance, the energy-turnaround-act 2021 in Germany was only passed on December $17^{\text {th }}, 2020$. Many owners of a PV system, which had dropped out of the subsidy after 20 years, were faced with the question of how they could continue to operate their PV power plant cost-efficiently in 2021. For legal factors to become more of a blessing than a curse for operators of sustainable energy plants in the long term, regulations should be planned and adapted in a sufficiently timely manner. Short-term changes or expiring substitution plans without sufficient follow-up regulations can undermine ongoing and planned business models and cause sustainable energy projects to fail. Policy makers must be aware of the long-term and far-reaching significance of regulations, and substitution programs in particular should therefore always be accompanied by adequate follow-up plans.

Societal factors were seen rather as a driving factor of new business models, above all an evident shift in thinking and increasing openness to smart and sustainable technologies. But at the same time a certain lack of willingness to pay higher prices for smart and sustainable products and services, as well as a lack of technology acceptance and NIMBY tendencies were seen as a key barrier for new business models in the energy sector. In this context a kind of contradiction in consumer expectations can be observed. It seems that in addition to an increasing number of environmentally conscious consumers who demand energy from sustainable sources, there is still a group of consumers who are not willing to accept new technologies and strictly reject new construction of sustainable energy plants, especially in their immediate living environment. As a possible solution, it is important to provide sufficient information, to involve local public institutions and to get citizens on board at an early stage, e.g. in construction projects (Wüstenhagen, Wolsink and Bürger, 2007; Huijts, Molin and Steg, 2012). By informing citizens and giving them the opportunity to voice questions and suggestions and thus help shape the projects, some of the social barriers could be overcome.

Technology was neither explicitly seen as a barrier nor as a driver for new business models. However, it was emphasized that the central technologies are mostly available and therefore the prevailing barriers for implementing new business models lie in other areas. In this context, it should be highlighted that the interviewees referred to business models and energy projects from their immediate work context, mostly local decentralized renewable energy projects with rather established technologies. In other contexts where the focus is on the development of very novel technologies, such as in startups, practitioners might often be confronted with a variety of more technological barriers. Therefore, it should not be assumed that all technological barriers have in fact been solved, but that technological barriers do not play a sufficiently large role for the implementation of renewable energy projects by established energy companies.

The presented study contains a few limitations. Firstly, the study does not provide an overarching picture of all the activities of energy suppliers and consultants in the field of smart energy but focuses on new business ideas and developments. The central aim of the study was to identify the factors most relevant in practice, and this focus on barriers and drivers relevant in practice might give the impression of a strong simplification. When looking at the driving and hindering factors, it must be emphasized, especially regarding the regulatory framework, that the results are not easily transferable to other markets. A distinction must be made for the individual barriers and drivers as to whether they also have the same significance in practice in other application areas, such as in corporate research and development or in the startup context. This study can provide a framework for doing so. Nonetheless, the method of conducting qualitative, semistructured interviews was well suited for gaining a deeper understanding of the locally applicable barriers and driving factors relevant in practice. The methodology provided valuable insights into the topic and provided suggestions on how barriers can be addressed in practice and how success factors can be used to best implement new business models in the renewable energy sector. 


\section{CONCLUSION}

The aim of the study was to summarize and clearly present barriers and drivers from different areas in a comprehensive framework to provide practitioners, researchers, and legislators with a basis for decision-making. The identified drivers and barriers were therefore evaluated, summarized and recommendations for practical action were proposed. Six categories of transformation barriers were identified: Organizational, Financial, Legal, Partner-Network, Societal and Technological barriers. Interestingly, organizational factors, especially an anti-innovative corporate structure and culture, as well as financial factors such as a lack of resources and strong competition were cited as the main obstacles. Increasing complexity and volatility due to changing regulations were also emphasized, followed by an increasing dependence on external partners due to multi-actor business models. Societal and technological barriers were considered less significant, with descriptions that societal acceptance of smart and sustainable technologies is increasing and that technologies to implement smart and sustainable business models are largely available. An area of improvement was seen, particularly regarding the ITinfrastructure within energy companies.

To overcome these barriers, recommendations for action by the experts and key success factors are outlined. In the area of organizational drivers, a service and customer orientation of the energy companies as well as a corporate culture open to innovation and change were emphasized above all. Among the transformation drivers related to partner network-related factors, the gain from external expertise and the exchange of experience and knowledge generated by it were emphasized. Financial factors, such as the importance of investments in smart and sustainable technologies were also underlined as decisive transformation drivers. In the context of the legal drivers, financial factors such as the added value of long-term financial security through public funding and subsidies were significant. In the context of societal drivers, an increased environmental awareness of the population was emphasized, which shapes the willingness to actively promote the energy turnaround. An economic downturn was named a beneficial factor, as it could increase companies' urgency to transform their business models. Technological drivers were not explicitly put in the foreground, but it was emphasized that the technologies needed to implement smart and sustainable business models are usually available, albeit still at a higher price.

Future research could start by examining the barriers and drivers relevant to practice in other regions and contexts to find out which factors stand out internationally. In addition, further research is needed around practice-relevant success factors. This study presented a range of success factors that were considered relevant by the experts interviewed, including, for example, the success factors of working within the framework of network business models. Further research should start by investigating the external validity of these success factors in practice. Finally, another research approach would be to consider the views of additional stakeholders from the energy domain. The present study focuses on experts from the field of energy supply and energy consulting; these findings could now be compared with the experiences of experts from other fields, e.g., experts from the legal field of regulation and subsidy.

\section{ACKNOWLEDGEMENTS}

The conducted research was part of a public funded interdisciplinary research project named ENsource (www.ensource.de), which focuses on decentralized, flexible solutions for future energy production and distribution in Germany. This project was funded from 2015 - 2020 by the Ministry of Science, Research and the Arts of the State of Baden-Wuerttemberg, Germany and the European Regional Development Fund (EFRE)

\section{REFERENCES}

Aslani, A. and Mohaghar, A. (2013) 'Business structure in renewable energy industry: Key areas', Renewable and Sustainable Energy Reviews. Elsevier, 27, pp. 569-575. doi: 10.1016/j.rser.2013.07.021.

Bocken, N. M. P. et al. (2014) 'A literature and practice review to develop sustainable business model archetypes', Journal of Cleaner Production. Elsevier Ltd, 65, pp. 42-56. doi: 10.1016/j.jclepro.2013.11.039.

Burger, S. P. and Luke, M. (2017) 'Business models for distributed energy resources: A review and empirical analysis', Energy Policy. Elsevier Ltd, 109(June), pp. 230-248. doi: 10.1016/j.enpol.2017.07.007.

Chang, P.-L. et al. (2011) 'Constructing a new business model for fermentative hydrogen production from wastewater treatment', International Journal of Hydrogen Energy, 36(21), pp. 13914-13921. doi: https://doi.org/10.1016/j.ijhydene.2011.03.066.

Chesbrough, H. (2010) 'Business model innovation: Opportunities and barriers', Long Range Planning. Elsevier Ltd, 43(2-3), pp. 354-363. doi: 10.1016/j.lrp.2009.07.010.

Dewald, J. (2018) 'E T \& P Storm Clouds and Silver Linings: Responding to Resilience', (January 2010). doi: 10.1111/j.15406520.2009.00312.x.

Doleski, O. D. (2014) 'Entwicklung neuer Geschäftsmodelle für die Energiewirtschaft - das Integrierte Geschäftsmodell', in Aichele, C. and Doleski, O. D. (eds) Smart Market: Vom Smart Grid zum intelligenten Energiemarkt. Wiesbaden: Springer, pp. 643-703.

Echterhoff, B., Hirschter, T. and Gausemeier, J. (2016) 'Systematic Business Model Implementation - From Concepts to Real Business', ISPIM Conference Proceedings, (June), pp. $1-20$.

Eleftheriadis, I. M. and Anagnostopoulou, E. G. (2015) 'Identifying barriers in the diffusion of renewable energy sources', Energy Policy. Elsevier, 80, pp. 153-164. doi: 10.1016/j.enpol.2015.01.039.

Engelken, M. et al. (2016) 'Comparing drivers, barriers, and opportunities of business models for renewable energies: A review', Renewable and Sustainable Energy Reviews, 60, pp. 795-809. doi: 10.1016/j.rser.2015.12.163.

Fauser, J. et al. (2019) 'Business model transformation in the energy sector: A literature review about barriers in the transformation process', in Proceedings of the Central European Conference on Information and Intelligent Systems, Varazdin, Croatia, pp. 187-194. 
Funkhouser, E. et al. (2015) 'Energy Research \& Social Science Business model innovations for deploying distributed generation: The emerging landscape of community solar in the U . S .', Chemical Physics Letters. Elsevier Ltd, 10, pp. 90-101. doi: 10.1016/j.erss.2015.07.004.

Hellström, M. et al. (2015) 'Collaboration mechanisms for business models in distributed energy ecosystems', Journal of Cleaner Production, 102, pp. 226-236. doi: 10.1016/j.jclepro.2015.04.128.

Horváth, D. and Szabó, R. Z. (2018) 'Evolution of photovoltaic business models: Overcoming the main barriers of distributed energy deployment', Renewable and Sustainable Energy Reviews. Elsevier Ltd, 90(July), pp. 623-635. doi: 10.1016/j.rser.2018.03.101.

Huijts, N. M. A., Molin, E. J. E. and Steg, L. (2012) 'Psychological factors influencing sustainable energy technology acceptance: A review-based comprehensive framework', Renewable and Sustainable Energy Reviews. Elsevier Ltd, 16(1), pp. 525-531. doi: 10.1016/j.rser.2011.08.018.

Jolly, S., Raven, R. and Romijn, H. (2012) 'Upscaling of business model experiments in off-grid PV solar energy in India Upscaling of business model experiments in off-grid PV solar energy in India'. doi: 10.1007/s11625-012-0163-7.

Koppenhoefer, C., Fauser, J. and Hertweck, D. (2018) 'MultiModel-Approach Towards Decentralized Corporate Energy Systems', in Otjacques, B. et al. (eds) From Science to Society: New Trends in Environmental Informatics. Cham: Springer International Publishing, pp. 117-128. doi: 10.1007/978-3-31965687-8_11.

Koppenhöfer, C., Fauser, J. and Hertweck, D. (2017) 'Digitization of Decentralized Corporate Energy Systems: Supportive best-practiced methods for the energy domain', in Rossmann, A. and Zimmermann, A. (eds). Böblingen, Bonn: Lecture Notes in Informatics, pp. 91-106.

Kotilainen, K. et al. (2016) 'Prosumer centric digital energy ecosystem framework', in Proceedings of the 8th International Conference on Management of Digital EcoSystems. New York, NY, USA: ACM, pp. 47-51. doi: 10.1145/3012071.3012080.

Kuckartz, U. (2014) Qualitative text analysis: A guide to methods, practice and using software. Sage.

Mautz, R. (2006) 'Der Ausbau der regenerativen Energien Chancen und Barrieren', SOFI Mitteilungen, 34(34), pp. 29-41.

Ojala, P. (2001) 'Business Plan Model for Bio-energy Companies’, pp. 47-52.

Osterwalder, A. et al. (2010) Business Model Generation. 1st edn, Booksgooglecom. 1st edn. Hoboken, New Jersey: John Wiley \& Sons. doi: 10.1523/JNEUROSCI.0307-10.2010.

Osterwalder, A. et al. (2014) Value Proposition Design: How to Create Products and Services Customers Want. John Wiley \& Sons.

Peppard, J. and Rylander, A. (2006) 'From Value Chain to
Value Network: Insights for Mobile Operators', European Management Journal, 24(2-3), pp. 128-141. doi: 10.1016/j.emj.2006.03.003.

Reiche, D. and Bechberger, M. (2004) 'Policy differences in the promotion of renewable energies in the EU member states', Energy Policy, 32(7), pp. 843-849. doi: 10.1016/S03014215(02)00343-9.

Richter, M. (2011) Mastering the Energy Transition: A Review on Utilities' Business Models for Renewable Energies. Lüneburg: CSM, Centre for Sustainability Management.

Richter, M. (2013a) 'Business model innovation for sustainable energy: German utilities and renewable energy', Energy Policy, 62, pp. 1226-1237. doi: 10.1016/j.enpol.2013.05.038.

Richter, M. (2013b) 'German utilities and distributed PV: How to overcome barriers to business model innovation', Renewable Energy. Elsevier Ltd, 55, pp. 456-466. doi: 10.1016/j.renene.2012.12.052.

Ruggiero, S., Varho, V. and Rikkonen, P. (2015) 'Transition to distributed energy generation in Finland: Prospects and barriers', Energy Policy. Elsevier, 86, pp. 433-443. doi: 10.1016/j.enpol.2015.07.024.

Wirtz, B. W. and Daiser, P. (2018) 'Business Model Innovation Processes: A Systematic Literature Review', Journal of Business Models, 6(1), pp. 40-58. doi: 10.5278/OJS.JBM.V6I1.2397.

Wüstenhagen, R., Wolsink, M. and Bürger, M. J. (2007) 'Social acceptance of renewable energy innovation: An introduction to the concept', 35, pp. 2683-2691. doi: 10.1016/j.enpol.2006.12.001.

Zhang, C. et al. (2017) 'From Numerical Model to Computational Intelligence: The Digital Transition of Urban Energy System', Energy Procedia. Elsevier B.V., 143, pp. 884890. doi: 10.1016/j.egypro.2017.12.778. 